\title{
Violência e Serviço Social: notas críticas
}

\author{
José Fernando Siqueira da Silva \\ Universidade Estadual Paulista (UNESP-Franca)
}

Violência e Serviço social: notas críticas

Resumo: O ensaio teórico apresentado tece algumas importantes observações sobre a violência como um complexo social que indica demandas particulares ao Serviço Social. Sugere, ao mesmo tempo, pistas para um tratamento crítico dessa importante categoria presente no próprio exercício profissional do assistente social. Reivindica, para tanto, a perspectiva da totalidade enfatizando a unidade-diversa entre a ontologia (a existência do ser social) e a gnosiologia (o conhecimento sobre esse ser), considerando a reconstrução do tema proposto como 'concreto pensado'.

Palavras-chave: violência, Serviço Social, formação profissional, trabalho profissional.

\section{Violence and Social Work: Critical Notes}

Abstract: This theoretical essay presents some important observations about violence as a social phenomenon that places particular demands upon Social Work. It suggests ways to handle this critical category of Social Work. It works from the perspective of totality, emphasizing the diverse unity between ontology (the existence of a social being) and gnosology (knowledge about this being), considering the reconstruction of the issue proposed as 'concrete thought'.

Key words: violence, Social Work, professional education, professional work. 


\section{Situando empiricamente o tema no Serviço Social}

Em geral, a fúria da violência tem algo a ver com a destruição do 'outro', 'diferente', 'estranho', com o que busca a purificação da sociedade, o exorcismo de dilemas difíceis, a sublimação do absurdo embutido nas formas de sociabilidade e nos jogos das forças sociais [...] (IANNI, 2004, p. 168, grifos do autor).

Analisar as múltiplas expressões da violência na contemporaneidade e suas relações com o Serviço Social nos diversos espaços socioocupacionais em que os assistentes sociais atuam profissionalmente (IAMAMOTO; CARVALHO, 1985), é condição básica para um exercício teórico-prático crítico que se proponha a perseguir, perquirir e reconstruir (ainda que não exatamente) o movimento do real como 'concreto pesado' (MARX, 1989). Trata-se de uma iniciativa que, certamente, não se limita ao Serviço Social, mas o desafia no sentido de discutir a violência como uma categoria que se objetiva (heterogeneamente, mas não isoladamente), sob dadas condições sócio-históricas, como um complexo social que envolve essa profissão e seus profissionais e exige deles posicionamentos e ações que possam criar, reafirmar ou inibir processos violentos.

Uma referência mais cuidadosa sobre as demandas enfrentadas pelo Serviço Social brasileiro na era da pós-reestruturação produtiva (marcada pela crise permanente do capital e por seus amplos impactos nos Estados e no mundo do trabalho), pode ser esboçada por meio das produções teóricas, apresentadas pelos assistentes sociais nos principais congressos e encontros dessa categoria profissional a partir da virada do século $20^{1}$. A sistematização inicial dessas informações permite afirmar que 3,99\% dos trabalhos aprovados fazem uma referência direta à violência. Dos cerca de 4.860 estudos que podem ser acessados, 194 indicam a violência como eixo analítico central. É relevante afirmar que 69\% desses trabalhos concentraram-se nos encontros em Recife (X Encontro Nacional de Pesquisadores em Serviço Social - ENPESS, 2006) e em Foz Iguaçu (XII Congresso Brasileiro de Assistentes Sociais CBAS, 2007), o que endossa a presença inegável do tema no âmbito da categoria dos assistentes sociais e, ao mesmo tempo, permite inferir um recente adensamento da visibilidade dessa discussão no campo profissional.

A sistematização inicial dos dados desses encontros revela, ainda que com inegáveis limites, informações interessantes. Apesar do risco de oferecer uma categorização limitada (de difícil precisão e organização - em vista da diversidade dos estudos apresentados na interface com o Serviço Social), é possível captar um padrão e sistematizá-los em itens afins, que revelam contextos cotidianamente enfrentados pelos profissionais de Serviço Social. Não se pretende, com a indicação desses itens, alegar que haja uma ruptura - ou promovê-la - entre as áreas indicadas; ao contrário, existe entre elas um nível de interlocução que, porém, não é direto e mecânico².

Posto isto, é possível indicar os seguintes eixos de análise da categoria violência nos recentes estudos de Serviço Social (2000-2007): violência e gênero $20,10 \%$; violência, Estado, violação de direitos e questão urbana - $19,59 \%$; violência doméstica - 14,43\%; violência, juventude, criminalidade e drogadição $12,37 \%$; violência e relações familiares $-8,25 \%$; violência sexual $-8,25 \%$; violência e instituição $4,64 \%$; violência e exercício profissional do assistente social $-3,61 \%$; violência e idosos $-3,61 \%$; violência e educação - $2,58 \%$; violência e religião - 1,03\%; violência estrutural-econômica $-1,03 \%$; violência e meios de comunicação de massa $-0,51 \%$.

Se forem consideradas somente as informações obtidas até o ano de 2004 (tendo como referência o XI Congresso Brasileiro realizado na cidade de Fortaleza), a violência, predominantemente citada pelos assistentes sociais, está associada a agressões no âmbito doméstico e no das questões de gênero (até aquela oportunidade perfazendo um total de $43,48 \%$ das indicações). No mesmo período, esse índice amplia-se ainda mais se forem observadas as possíveis - mas não necessárias - vinculações entre violência e gênero $(24,35 \%)$, violência doméstica $(19,13 \%)$, relações familiares $(9,56 \%)$ e violência sexual $(8,69 \%)$, totalizando um índice significativo de $61,73 \%$.

$\mathrm{Se}$, forem inseridas nesse cálculo, as informações dos encontros em Recife e em Foz do Iguaçu, os dados mostram um aumento na preocupação da categoria profissional com os itens 'violência, juventude, criminalidade e drogadição' (que saltou de 5,22\% em 2004 para 12,37\% em 2007) e 'violência, Estado, violação de direitos e questão urbana' (de 18,26\% para $19,59 \%$, no mesmo período). Ao mesmo tempo, há um recuo nos índices dos estudos sobre 'violência e gênero' (de 24,35\% até 2004 para 20,10\% em 2007), 'violência doméstica' (de 19,13\% para 14,43\%), 'violência e relações familiares' (de 9,56\% para 8,25\%) e 'violência sexual' (de 8,69\% para 8,25\%). Mesmo assim, a presença final desses últimos itens conjuntamente continua significativa: $51,03 \%$ (portanto, mais que a metade das produções, ainda que inferior ao considerável índice constatado até 2004: 61,73\%). Há de se ressaltar, um crescimento da preocupação dos assistentes sociais com a discussão de assuntos que relacionam 'violência e idosos' (que saltou de 1,74\% em 2004 para 3,61\% em 2007) e 'violência e instituição' (de $0,87 \%$ para $4,64 \%$ ).

Vale registrar, no entanto, que a indicação dessas 'áreas de intersecção' entre a atuação profissional do assistente social e a violência (em algumas de suas 
mais importantes expressões - tendo como referência os eventos citados), não significa, em absoluto, que elas sejam as únicas realmente materializadas. O não registro de outras dimensões não significa, necessariamente, a inexistência delas no cotidiano profissional. Isso pode ocorrer por falta de apropriação de demandas existentes ou, simplesmente, por impossibilidade ou dificuldade de chegarem aos principais eventos, e serem aprovadas e publicadas nos seus anais. Podese, por exemplo, considerar a violência não apenas como um complexo social, que se objetiva na atuação do assistente social, motivada por um 'elemento externo' a ela (uma demanda apresentada à profissão: a mulher violentada, a criança espancada ou a violência urbana em suas diversas manifestações, entre outras), mas, também, como um processo que se reconstrói a partir da própria intervenção profissional. Nesta acepção a violência adquire, inclusive, outros desdobramentos que a colocam como parte constituinte de um circuito violento (isso foi indicado no item 'violência e exercício profissional do assistente social' 3,61\%). Essa é uma dimensão particularmente interessante que não pode ser subestimada em qualquer discussão sobre a violência, as suas múltiplas expressões e o Serviço Social.

Os dados relatados, apesar dos limites, são suficientes para evidenciar que os assistentes sociais possuem uma inserção profissional altamente relevante no campo da violência (embora isso nem sempre pareça claro para eles próprios), espaço esse que pode e deve servir como um verdadeiro celeiro empírico necessário e insuprimível, apontando para o ponto de partida e o de chegada da práxis profissional. Em outras palavras, trata-se de um profissional empiricamente privilegiado por ocupar os confins da sociedade burguesa abrasileirada e atuar concretamente frente a esse impacto (sobretudo no campo das políticas sociais - seja na reprodução da força de trabalho, ou na simples manutenção dos miseráveis). Ao mesmo tempo, parece que - e esse é um segundo aspecto relevante vem crescendo a sintonia entre as múltiplas inserções desse profissional e alguns setores da academia, comprometidos com a produção de conhecimentos relacionados à violência.

Por outro lado, o grande desafio continua sendo o de qualificar a forma como essa riqueza empírica é apropriada teoricamente pelos assistentes sociais e como isso é socializado com os diferentes segmentos da profissão. O problema está, sobretudo, na pro- funda dificuldade desses profissionais apanharem as particularidades da violência a partir de suas manifestações imediatas e singulares no espaço em que se materializa a atuação profissional. Cria-se, então, um cenário perverso: o mesmo ingrediente necessário para uma densa apropriação do movimento do real (a vivência de experiências concretas), quando tomado isoladamente, consome a força, o potencial criativo do assistente social na divisão do trabalho, atribuindo-lhe a responsabilidade de 'gerenciar praticamente' mazelas sociais, oriundas da violência estrutural, implícita no próprio metabolismo do capitalismo contemporâneo, que é objetivada, com certa independência, por meio de ações violentas, também potencializadas por individualidades e suas respectivas subjetividades.

Consolida-se, então, um terreno fértil para certo tipo de fragmentação teórica e prática que se estende à categoria violência, (eliminando uma em favor da outra, ou simplesmente ressaltando uma delas como a esfera que interessa à profissão), e, ao mesmo tempo, reforça-se um procedimento formativo, comprometido com a criação de especialistas (teóricos ou práticos) que atuem nas expressões das 'violências singulares' (como se essa dimensão - componente insuprimível da categoria da totalidade - não fosse saturada por características universais e particulares). Essa ruptura entre o fazer e o pensar (já explicitamente relatada por Marx na segunda metade do século 19 MARX, 1983), essa dificuldade de apanhar - ainda que relativamente - a realidade como totalidade (em movimento), é determinada e reforçada pela estrutura da ordem burguesa e encontra ecos profundos na profissão. Nesse contexto, a formação teórica fragmentada, deficitária ou simplesmente 'aplicada" às necessidades imediatas dos assistentes sociais, é mais uma questão imposta à profissão.

Embora não seja possível, nesse curto espaço, analisar o conteúdo dos estudos apresentados pelas comunicações selecionadas a partir dos anais dos eventos considerados (e esse não é o objetivo desse artigo), essa abordagem preliminar sobre elas confirma sua diversidade teórica e temática. Transitam da sistematização de práticas interessantes que remetem a situações desafiadoras, apresentadas aos profissionais de Serviço Social, propiciando múltiplas análises sustentadas em diversas orientações teóricas ou fragmentos delas. Reivindicam, pelo menos intencionalmente, 
a defesa de direitos e a denúncia de todas as formas de violência sob a orientação do Código de Ética e do projeto ético-político da profissão.

Ora, reivindicar isso não é pouco, embora seja, certamente, insuficiente para sintonizar a profissão sem idealismos - com as inúmeras discussões que emergem do campo da violência. Cabe salientar, aqui, a necessidade de não apenas sistematizar experiências (por melhor e mais elaboradas que sejam) e, ao mesmo tempo, não afirmar qualquer tradição teórica (muito menos aquelas comprometidas com sínteses ecléticas). Para além desse nível que 'adoça a boca' dos amantes da pós-modernidade, é necessário ressaltar uma tradição teórica que permita forcejar o projeto ético-político da profissão e questionar as possibilidades e os limites da emancipação política (MARX, 2005a, p. 41-42). É preciso afirmar que a produção de conhecimentos, comprometida com a perspectiva da totalidade (no sentido em que foi tratada por Marx e explicitada por Lukács), fornece as melhores condições para isso, embora não garanta em absoluto e por si só - um sucesso do pesquisador que assuma esse ponto de vista (LÖWY, 1988).

Portanto, embora a focalização, a fragmentação e a departamentalização sejam características implícitas no próprio metabolismo da ordem burguesa em curso (com suas derivações mais elaboradas que valorizam, com maior ou menor intensidade, a 'rede comunicativa', estabelecida entre as partes para a 'estabilidade' do todo - CAPRA, 2004) é preciso ressaltar os tipos de abordagem e de tratamento oferecidos pelos estudos e a forma como esse conhecimento vem sendo apropriado pelos assistentes sociais, tendo como ponto de partida as inserções concretas da profissão na contemporaneidade. Valorizar esse aspecto dentro da perspectiva da totalidade - construída na unidade-diversa entre a teoria e a prática, entre o pensamento e a realidade, entre a ontologia e a gnosiologia e apanhada na trama estabelecida entre o singular, o universal e o particular (LUKÁCS, 1979, p. 27) - é condição básica para que os assistentes sociais apreendam criticamente as demandas imediatamente enfrentadas, potencializem positivamente essa relação, qualifiquem as possibilidades e os limites da emancipação política em questão e sintonizem a profissão, sem qualquer idealismo, com a emancipação humana (MARX, 2005a). Esse é, segundo nossa opinião, o caminho mais fecundo para forcejar, nas suas fronteiras e contradições, o Código de Ética dos assistentes sociais e seu projeto ético-políti- co. Tal procedimento é absolutamente necessário para que seja construída uma abordagem séria, densa e comprometida capaz de combater qualquer forma particular de violência que se apresente como demanda ao assistente social ou que se reproduza com o aval consciente ou não - do profissional e de sua atuação.

\section{A violência como complexo social e sua reconstrução como categoria de análise}

Argumentou-se, até o presente momento, que o prévio mapeamento empírico das múltiplas expressões contemporâneas da violência na relação direta com o Serviço Social deve servir de referência à práxis profissional. É preciso não apenas qualificar a apropriação da dinâmica desse real, mas, ao mesmo tempo, fomentar condições para que a produção elaborada tenha impactos efetivos no cotidiano (HELLER, 1989) profissional. Desconsiderar essa dimensão insuprimível como tal - na produção de conhecimentos ou, ao contrário, se limitar a sua face singular e imediata, inviabiliza qualquer iniciativa comprometida com a reconstrução da violência como categoria sócio-histórica que se objetiva como complexo social. Esse é um procedimento imprescindível atualmente para o Serviço Social.

A violência, em suas diversas manifestações contemporâneas mais imediatamente visíveis (física, psicológica, simbólica, estrutural ou a associação entre elas), possui uma existência real que impacta a vida de seres sociais sob dada historicidade. Sua objetivação não é uma abstração e supõe, necessariamente, para que seja violência, uma realização prática - mais ou menos visível, reconhecida ou não socialmente - capaz de violar, oprimir, constranger ferir e impor interesses e vontades que se sustentam em desejos de indivíduos sociais, situados em uma dada existência que impõe os parâmetros por onde tais subjetividades se formam e se desenvolvem. Portanto, por mais pontual que possa parecer um ato violento, ele sempre será ideado, viabilizado e explicado sob determinadas condições sócio-históricas e, evidentemente, não poderá ficar circunscrito à esfera puramente individual-subjetiva (embora não prescinda dela), já que o ser social é, ao mesmo tempo, subjetividade-objetividade, indivíduo-classe. A violência, nas suas diversas expressões, é uma categoria que se realiza como complexo social, que pertence às relações humano-sociais (longe de qualquer 
paradigma biologista) e que carece, para seu enfretamento, de reconstrução crítica apoiada na razão que se debruça sobre o mundo e, a partir dele, formula conceitos e propõe alternativas práticas.

Entretanto, como categoria que também é sistematizada por meio de conceitos, a violência não está circunscrita a um ou outro conceito. Trata-se de um acontecimento excepcional - material - que revela dimensões desconhecidas da vida social, produzindo impactos econômicos, políticos e socioculturais. A violência conta com seres reais que a operacionalizam com uso da força (não necessariamente física), com certa intensidade, com finalidades, intenções e interesses diversos. Revela, no geral, como lembra Ianni (2004, p. 168), um desejo de destruição do outro, daquele que é 'diferente' e 'estranho', que foge dos padrões socialmente estabelecidos. Procura, com isto, exorcizar questões de difícil solução e sublimar situações e cenários absurdos, embutidos na sociabilidade e no jogo de forças sociais ${ }^{3}$. Isso, por si só, indica os imensos desafios que se apresentam ao Serviço Social e à formação de seus profissionais.

Apanhar, neste contexto, a violência como categoria de análise exige um procedimento metodológico comprometido com a perspectiva da totalidade - que também, como categoria ontológica, possui uma existência para além da razão pensante. Em outras palavras, longe de qualquer tentativa de fragmentar ou de generalizar mecanicamente a explicação da violência nas suas heterogêneas formas de objetivação, é preciso partir das demandas imediatas impostas à profissão e descortinar suas conexões universais reais que jamais se realizam como atos unicamente isolados. No entanto, isso somente adquire maior concretude na medida em que as particularidades da violência como complexo social e suas inúmeras mediações reconstruídas com o auxílio da razão, sejam explicadas para além das manifestações imediatamente constatadas pelos assistentes sociais em seu trabalho. É preciso, mais do que isso, que todo esse processo volte ao seu 'ponto de partida' e oriente a intervenção profissional sem idealismos, ou seja, sem exigir dela e do Serviço Social o que ambos não podem oferecer. Isso indica as grandes dificuldades para a concretização de uma leitura de totalidade em tempos de fragmentação generalizada.

[...] O concreto é concreto, porque é a concentração de muitas determinações, isto é, unidade do diverso. Por isso, o concreto aparece no pensamento como o processo de concentração, como resultado, não como ponto de partida e, portanto, o ponto de partida também da intuição e da representação. No primeiro caminho a representação plena volatiliza-se na determinação abstrata ${ }^{4}$; no segundo, as determinações abstratas conduzem à reprodução do concreto por meio do pensamento.
Assim é que Hegel chegou à ilusão de conceber o real como resultado do pensamento que se concentra, que se aprofunda em si mesmo e se apreende a partir de si mesmo como pensamento móvel; enquanto que o método que consiste em elevar-se do abstrato ao concreto não é senão a maneira de proceder do pensamento para se apropriar do concreto, para reproduzi-lo espiritualmente como coisa concreta [...] (MARX, 1989, p. 410).

É importante salientar que a existência de diferentes formas de apreensão do real (marcadas por bases teóricas diferenciadas e por orientações de classe igualmente diferentes), não elimina, em absoluto, a existência de uma verdade sobre esse real (a sua lógica concreta). Nós a perseguimos, se a capturamos, ainda que nunca exatamente, é outro problema. $\mathrm{O}$ mesmo ocorre com as diferentes apreensões sobre a categoria violência e o significado da desigualdade social na ordem burguesa madura 'abrasileirada', contaminadas por formas ideológicas que tomam parte do processo como sendo o processo por inteiro. Por isso, com não pouca freqüência, são endossadas apreensões da 'violência' ou de 'violências' (na verdade formas particulares de objetivação cotidiana da violência) como atos pontuais causados exclusivamente por indivíduos que carecem de um tratamento focal.

Essa deturpação se estende para outras importantes categorias abstratamente referenciadas: a democracia, a cidadania, a liberdade, a autonomia, a justiça, a eqüidade, os direitos e a emancipação. Todas elas necessárias para uma abordagem de totalidade, mas freqüentemente consideradas como 'uma outra coisa' quando se fala de violência. Ora, é necessário explicar o que representam, do que tratam e em qual sentido são apropriadas e reproduzidas tais terminologias no âmbito da profissão, também quando se discutem as expressões particulares da violência! Por exemplo: de qual democracia falamos? Ela é a referência para o que se chama de emancipação? Qual tipo de emancipação? Qual a utilidade delas no combate às múltiplas manifestações da violência na contemporaneidade, desde a leitura crítica desse complexo social (para além da culpabilização meramente individual) até a formulação de ações efetivas para sua negaçãosuperação? O mesmo vale para os outros termos tomados, muitas vezes, sem qualquer rigor - o eixo exclusão-inclusão social, por exemplo -, como referências indiscutíveis à construção genérica de uma 'outra ordem societária' (diga-se de passagem, uma tarefa que não se limita, jamais, às profissões).

Analisar com cuidado esse pantanoso e contraditório terreno por onde se move a profissão, é condição básica para uma abordagem séria da violência no âmbito da formação e do trabalho do assistente social, seja em relação às formas de violência 
que fazem parte da vida cotidiana dos usuários ou, o que é especialmente interessante, àquelas que se propagam com a colaboração dos profissionais (e elas freqüentemente 'dialogam' entre si).

As desigualdades sociais particularizadas e fundamentadas, sob as condições objetivas oferecidas pelo capitalismo (a apropriação privada da produção social), possibilitam a materialização de diferentes formas de violência. Esse aspecto relacionado à questão social - intrínseca à natureza da propriedade privada (MARX, 1984, p. 187) -, precisa ser considerado na formação profissional do assistente social ao se discutir as expressões da violência no Serviço Social. Não se trata, então, de fomentar abordagens segmentadas da violência no processo de formação profissional, mas de reconstruí-la como elemento que se repete e se particulariza - não mecanicamente - sob condições históricas, marcadas pela crise do capital e de suas contraditórias iniciativas de reprodução em escala ampliada.

Nesse sentido é que, por exemplo, a violência particularizada em 'múltiplas faces' (diferentes, mas unidas entre si), não carece, necessariamente, de um espaço específico nas grades curriculares dos cursos de Serviço Social, mas, sobretudo, deve ser abordada e destacada na interface entre a profissão e os assuntos que servem como eixo central para importantes conteúdos programáticos, materializados em ementas de disciplinas: Fundamentos Teóricos-Históricos-Filosóficos, Trabalho Profissional, Ética, Sociologia, Teoria Política, Filosofia, Psicologia, entre outras 5 . O estágio supervisionado, a supervisão acadêmica e de campo, no caso da graduação, devem ser interlocutores privilegiados para oferecer e discutir cenários reais vividos pelos discentes e pelos futuros profissionais.

Essa postura evita a fragmentação e o isolamento na própria forma de reconstruir o tema no âmbito da profissão (e no da formação), bem como estimula uma apropriação das expressões da violência tendo como base temas-eixo reais para o Serviço Social: questão social, Estado e políticas sociais, teoria/método/produção de conhecimentos, trabalho profissional, entre outros, considerando como terreno sócio-histórico a ordem burguesa contemporânea no Brasil. Existem, nesse sentido, melhores condições para apreender a violência como um importante complexo social que interage com o Serviço Social de múltiplas maneiras, sob dadas condições, desconstruindo interpretações que tendem a explicá-la como uma 'aberração' unicamente criada e praticada por indivíduos ou segmentos sociais 'predispostos' a comportamentos violentos, tomando formas particulares de violência como sendo 'a violência' (hoje, por exemplo, materializada na maldita 'violência urbana').
Crescem, simultaneamente, as possibilidades de uma análise mais densa sobre o papel da profissão e dos profissionais como atores que potencializam, ou não, processos violentos.

Reivindica-se, então, sem romantismos, um trabalho profissional, entendido como uma determinada forma de trabalho assalariado (necessariamente abstrato - que subsume, mas não elimina sua dimensão concreta), predominantemente improdutivo e claramente material (situado no campo das relações sociais e da reprodução da força de trabalho, especificamente relacionado com o gerenciamento de múltiplos programas e projetos sociais que fazem parte das políticas sociais - e esse é um dado insuprimível), dotado de uma formação profissional com densidade teórica e forte carisma interventivo (contexto em que deve se inserir a pesquisa e a produção de conhecimentos). Sob essas condições, sem qualquer concessão messiânica e com clareza de suas bases históricas nitidamente conservadoras (IAMAMOTO 1985, 1994; PAULO NETTO, 1991), é necessário valorizar o potencial criativo do sujeito histórico possível - que também o assistente social pode exercer - sobretudo nesses momentos em que a voracidade do capital estimula a criação e a recriação de múltiplas formas de violência com a participação, mais ou menos consciente, dos profissionais e das profissões. Não acreditar nessa possibilidade não apenas engessa a ambos, mas, sobretudo, os coloca no campo exclusivo da reprodução do capital (sem qualquer possibilidade de resistência) e a favor da violência em suas múltiplas expressões (mesmo que os assistentes sociais não se dêem conta disso). É preciso, portanto, qualificar a forma como o profissional ocupa espaços, apropriase criticamente deles e desenvolve ações.

A partir disso e dos limites intransponíveis determinados pelas possibilidades de uma profissão, dentro de sua história e de sua historicidade, que é possível reivindicar uma interlocução entre o Serviço Social, a contribuição marxiana e certa tradição marxista comprometida com a perspectiva da totalidade (inclusive no trato da categoria violência), sem crer, em absoluto, em um 'Serviço Social marxista' ou em um marxismo adaptado às condições de uma profissão (PAULO NETTO, 1989). Essas são as melhores condições - embora não sirvam de garantia absoluta - para dar combate radical à violência e às suas múltiplas expressões na contemporaneidade, valorizando uma inserção crítica e propositiva que potencialize importantes alternativas de resistência naqueles espaços socioocupacionais onde se possa, deva e tenha que pensar e fazer de forma diferente (como intelectuais e não como 'acadêmicos' ou 'práticos').

Nesse sentido, é possível qualificar a emancipação política e forcejar na direção da emancipação 
humana (MARX, 2005a, p. 42), sem atribuir à primeira o caminho mágico para a realização da segunda (LESSA, 2007).

\section{Apontamentos para a continuidade do debate}

O Serviço Social como profissão e os assistentes sociais como profissionais que exercem determinado tipo de trabalho, podem reforçar - com maior ou menor intensidade - processos violentos ou resistir a eles a partir das condições objetivas disponíveis. A violência e suas expressões particulares não são demandas puramente 'externas' que se apresentam à profissão para um tratamento técnico, eficiente e sistêmico. Mais do que isso, imbricam-se com o exercício profissional do assistente social e exigem dele um posicionamento teórico, político e prático - marcado pela necessária clareza teórico-analítica e pela solidez interventiva - que o coloca como um ator participante de um complexo circuito repleto de sutilezas e de armadilhas.

É preciso reconhecer que a violência apresentase heterogênea e multifacetada e se particulariza atingindo diferentes segmentos sociais (jovens, mulheres, idosos, famílias, grupos, movimentos sociais, entre outros), classes sociais diversas (dos miseráveis aos milionários - ainda que, evidentemente, objetive-se com intensidades variadas e conte com instrumentos de defesa igualmente diferentes e desiguais) e imediatamente se manifesta por meio de marcas físicas ou psicológicas, sentidas por indivíduos. Certamente que as expressões particulares da violência não estão circunscritas às camadas pobres, ainda que se materializem nelas sob condições peculiares (como vítimas ou agentes reprodutores). Mas é necessário reconhecer que as condições materiais de existência e a sociabilidade nela formada são componentes insuprimíveis para a explicação desse fenômeno mesmo que seja para ressaltar as faltas ou os excessos por onde as relações sociais - burguesas - constituem-se, cada vez mais, como 'relações coisais'.

Portanto, afirmar que processos violentos se particularizam sob determinadas condições e em determinados segmentos sociais, não é o mesmo que endossar uma abordagem focal da violência. Enfrentar as múltiplas formas atuais de violência não significa, em absoluto, especializar o 'olhar científico' para formar profissionais comprometidos com tratamentos e ações cirúrgicas, como verdadeiros 'médicos sociais'. Reafirmar a perspectiva da totalidade na reconstrução da violência como categoria e como complexo social possui o exato sentido de reconhecer, a absoluta necessidade de apanhar as particularidades da violência que se apresentam aos assistentes sociais e que podem continuar a se reproduzir - mais intensamente - com base em seu exercício profissional (como processo que atravessa a profissão e os profissionais inseridos nesse circuito). Apanhar esse contexto, reconhecer sua complexa e pulverizada (mas não isolada) particularização e, a partir disso, propor encaminhamentos práticos e efetivos que levem em consideração os aspectos peculiares dos segmentos envolvidos, é condição para o enfrentamento das múltiplas formas de violência. Entretanto, esse procedimento, em momento algum, não pode ser confundido com ações focais administradas por gerentes sociais especialistas em recortar o 'irrecortável'.

Nesse sentido, apontamos nos itens a seguir algumas iniciativas de resistência, necessárias para subsidiar ações individuais e coletivas.

a) E fundamental, insistir em uma formação profissional que, negando, simultaneamente, o 'academicismo' e o 'teoricismo', esteja voltada para a análise teórica de desafios práticos, enriquecendo a experiência com a reflexão crítica. Evidentemente que as atuais condições não são nada favoráveis para isso. A precarização da formação profissional, estimulada pela proliferação de cursos à distância - com amplo aval e estímulo das instâncias oficiais -, a 'flexibilização' e as inúmeras dificuldades dos cursos presenciais, a tendência em 'enxugar' a pós-graduação, entre outras iniciativas em curso, consolidam uma orientação educacional superficial e meramente operativa (ou nem isso), portanto muito distante da necessária base intelectual fundamental à práxis profissional.

b) É preciso ter claro, que os campos da emancipação política e da afirmação de direitos (MARX, 2005a) devem ser ocupados e potencializados pelos profissionais de Serviço Social. No entanto, somente vale a pena assumi-los se for possível imprimir uma direção que ocupe e movimente suas possibilidades por meio da práxis profissional. Isso significa ocupar espaços oficiais e institucionais (pelo menos aqueles que propiciam a contradição e o debate), ainda que estas instâncias sejam insuficientes. Assim, é preciso, entre outras coisas, preparar profissionais capazes de potencializar múltiplas instâncias que ponham em movimento forças comprometidas com a emancipação humana.

c) É necessário, retomar o vínculo com os movimentos sociais e com os trabalhos populares. Longe de qualquer iniciativa preocupada em ressuscitar ações sectárias e dogmáticas, mas para sintonizar o trabalho profissional com outras instâncias absolutamente necessárias à práxis social (MARX, 
1987). Como está expresso em Silva (2008), é fundamental abandonar o isolamento e a 'neutralidade' técnico-instrumental - o posto unicamente gerencial -, 'colar' no movimento do real e, portanto, produzir conhecimentos, propor e viabilizar alternativas a partir das necessidades dos segmentos sociais desapropriados pelo capital. Isso, simultaneamente, enriquece os espaços oficiais e gerenciais - importantes quando ocupados propositivamente - 'temperando-os' com potência contestatória e oxigenando possíveis comportamentos dóceis de lideranças cooptadas pelo instituído. Ao mesmo tempo, oferece informações institucionais valiosas aos movimentos sociais e contribui para criticá-los em suas fragilidades (particularmente na sua fragmentação), fortalecendo e concretizando suas ações. Esse procedimento qualifica o trabalho profissional e exige, dele, posturas absolutamente diferenciadas no campo teóricoprático e ético-político.

Um grande desafio está claramente posto ao Serviço Social: ou se caminha em direção a reafirmar o Código de Ética e o projeto ético-político da profissão no exato sentido de esclarecer e de radicalizar a apreensão teórico-prática de categorias sociais que dizem respeito à existência do ser na ordem burguesa (trabalho, questão social, democracia, emancipação, solidariedade, justiça, equidade, liberdade e, nessa trama, as manifestações particulares da violência), ou serão eliminadas quaisquer possibilidades de resistência e de reorganização das forças progressistas nesses duros tempos de supremacia do capital sobre o trabalho. Este é o caminho para sucumbir à desumanização do homem e reafirmar um Serviço Social limitado ao 'cidadão' consumidor responsável e comprometido com a 'solidariedade' de classes. Essas não seriam as condições ideais para a reprodução da violência e de suas expressões contemporâneas particulares no mundo do capital, considerando as bases criadas pela ideologia do 'humanismo solidário'?

\section{Referências}

CAPRA, F. O ponto de mutação - a ciência, a sociedade e a cultura emergente. São Paulo: Editora Cultrix, 2004.

HELLER, A. O cotidiano e a história. Rio de Janeiro: Paz e Terra, 1989.

IAMAMOTO, M. V. Renovação e conservadorismo no Serviço Social-ensaios críticos. São Paulo: Cortez/Celats, 1994.
.; CARVALHO, R. de. Relações sociais e Serviço Social no Brasil. Esboço de uma interpretação históricometodológica. São Paulo: Cortez, 1985.

IANNI, O. A cultura da violência. Capitalismo, violência e terrorismo. Rio de Janeiro: Civilização Brasileira, 2004.

LESSA, S. A emancipação política e a defesa de direitos. Revista Serviço Social \& Sociedade, São Paulo: Cortez, n. 90, p. 35-57, jun. 2007.

LÖWY, M. As aventuras de Karl Marx contra o barão de Münchausen. Marxismo e positivismo na sociologia do conhecimento. São Paulo: Busca Vida, 1988.

LUKÁCS, G. Introdução a uma estética marxista. Tradução de Carlos Nelson Coutinho. Rio de Janeiro: Civilização Brasileira, 1978.

Ontologia do ser social. Os princípios ontológicos fundamentais de Marx. São Paulo: Livraria Editora Ciências Humanas, 1979.

MARX, K. O método da economia política. Contribuição à crítica da economia política. In: FERNANDES, F. (Org.). Marx/Engels - História. São Paulo: Ática, 1989. (Coleção Grandes Cientistas Sociais, n. 36, p. 409-417). $2005 \mathrm{a}$

. A questão judaica. São Paulo: Centauro Editora,

. As teses sobre Feuerbach. A ideologia alemã. São Paulo: Hucitec, 1987.

O capital. São Paulo: Abril Cultural, 1984. (v. 1, t. 2).

PAUlO NETTO, J. Ditadura e Serviço Social - uma análise do Serviço Social no Brasil pós-64. São Paulo: Cortez, 1991.

- O Serviço Social e a tradição marxista. Serviço Social \& Sociedade, São Paulo: Cortez, n. 30, p. 89-102, abr. 1989.

SILVA, J. F. S. da. 'Justiceiros' e violência urbana. São Paulo: Cortez, 2004a.

. Violência, Serviço Social e formação profissional. Serviço Social \& Sociedade. São Paulo: Cortez, n. 79, p. 133-147, set. 2004b.

. O recrudescimento da violência nos espaços urbanos: desafios para o Serviço Social. Serviço Social \& Sociedade, São Paulo: Cortez, n. 89, p. 130-154, mar. 2007a.

. Pesquisa e produção do conhecimento em Serviço Social. Textos \& Contextos, PUCRS, v. 6, n. 2, dez. 2007 b. 
Disponível em: <http://revistaseletronicas.pucrs.br/fass/ ojs/index.php/fass>. Acesso em: 2 fev. 2007.

.Violência e desigualdade social: desafios contemporâneos para o Serviço Social. Revista Ser Social, Brasília: UnB, n. 19, p. 31-58, 2008.

\section{Notas}

1 São considerados, aqui, os trabalhos que reivindicam diretamente uma discussão sobre a violência a partir de suas expressões na área de Serviço Social, tendo como referência o período situado entre o VII Encontro Nacional de Pesquisadores em Serviço Social (Enpess, Brasília, 2000) e o XII Congresso Brasileiro de Assistentes Social (Foz do Iguaçu, 2007).

2 Análises focalistas empobrecem a explicação do movimento do real tanto quanto estudos puramente generalistas. É preciso indicar as mediações situadas na esfera da particularidade, apanhando a dinâmica entre o universal e o singular. Sobre isso consultar Lukács $(1978,1979)$.

3 Discussão feita em Silva(2007a-b, 2008).

4 Marx critica, aqui, o procedimento metodológico abstratoespeculativo dos economistas do século 17 que partia, sempre, de um "todo vivo: a população, a nação, o Estado, vários Estados etc."

5 Isso também vale para a pós-graduação em seus diferentes níveis(SILVA, 2004b).

\section{José Fernando Siqueira da Silva}

Doutor em Serviço Social pela Pontifícia Universidade Católica de São Paulo (PUC-SP)

Professor do Departamento de Serviço Social da Universidade Estadual Paulista (UNESP-Franca)

\section{UNESP-Franca}

Rua Major Claudiano, 1488, sala 157

Centro

Franca - São Paulo

Caixa Postal 211

CEP: 14400-690 